Squibb, Celgene, Crescendo, Genentech, Janssen, Eli Lilly and Company, Merck, Novartis, Pfizer, UCB Pharma, Sun, Consultant for: AbbVie, Amgen, Bristol Myers Squibb, Celgene, Crescendo, Genentech, Janssen, Eli Lilly and Company, Merck, Novartis, Pfizer, UCB Pharma, Sun, Speakers bureau: AbbVie, Amgen, Bristol Myers Squibb, Celgene, Crescendo, Genentech, Janssen, Pfizer, UCB Pharma DOI: 10.1136/annrheumdis-2017-eular.2221

\section{OP0222 SECUKINUMAB PROVIDES SUSTAINED IMPROVEMENTS IN THE SIGNS AND SYMPTOMS OF ACTIVE PSORIATIC ARTHRITIS: 104 WEEKS RESULTS FROM A PHASE 3 TRIAL, FUTURE 2}

I.B. McInnes ${ }^{1}$, P.J. Mease ${ }^{2}$, C. Ritchlin ${ }^{3}$, P. Rahman ${ }^{4}$, A. Gottlieb ${ }^{5}$, B. Kirkham ${ }^{6}$, R. Kajekar ${ }^{7}$, E.M. Delicha ${ }^{8}$, L. Pricop ${ }^{7}$, S. Mpofu ${ }^{8}$ on behalf of the FUTURE 2 study group. ${ }^{1}$ University of Glasgow, Glasgow, United Kingdom; ${ }^{2}$ Swedish Medical Centre and University of Washington, Seattle: ${ }^{3}$ University of Rochester, Rochester, United States; ${ }^{4}$ Memorial University, St. John's, Canada; ${ }^{5}$ New York Medical College, New York, United States; ${ }^{6}$ Guy's \& St Thomas' NHS Foundation Trust, London, United Kingdom: ${ }^{7}$ Novartis Pharmaceuticals Corporation, East Hanover, United States; ${ }^{8}$ Novartis Pharma AG, Basel, Switzerland

Background: Secukinumab significantly improved the signs and symptoms of psoriatic arthritis (PsA) over 52 weeks (wks) in FUTURE 2 study (NCT01752634). ${ }^{1,2}$ Objectives: To present longer-term (104 wks) efficacy and safety data of secukinumab from FUTURE 2 study.

Methods: Overall, 397 patients (pts) with active PsA were randomised to secukinumab $(300,150$, or $75 \mathrm{mg})$ or placebo at baseline, Wks $1,2,3$, and 4 , and every 4 wks thereafter. Assessments at Wk 104 are from pts originally randomised to secukinumab and included ACR20/50/70, PASI 75/90, DAS28CRP, SF-36 PCS, HAQ-DI, dactylitis, and enthesitis. Multiple imputation was used for analysis of binary variables and mixed-model repeated measures for continuous variables. Analyses stratified by anti-TNF $\alpha$ status (naïve/inadequate response or intolerance to these agents) were prespecified and are reported as observed. Safety analysis included all pts who received $\geq 1$ dose of secukinumab.

Results: In total, $86 / 100(86.0 \%), 76 / 100(76.0 \%)$ and $65 / 99(65.7 \%)$ pts in the secukinumab 300,150 , and $75 \mathrm{mg}$ groups respectively completed 104 wks. Sustained clinical improvements were observed through Wk 104 with secukinumab across all clinically important domains of PsA (Table). Responses were sustained through Wk 104 regardless of anti-TNF $\alpha$ status. Over the entire treatment period (mean $[ \pm S D]$ exposure to secukinumab of $709 \pm 210.99$ days), the exposure adjusted incidence rates for serious infections/infestations, candida infections, inflammatory bowel disease and malignant/unspecified tumors with secukinumab were $1.6,2.3,0.5$ and 1.3 , respectively.

Table 1. Summary of Efficacy Results at Wk 104

\begin{tabular}{lccc}
\hline Variable* & \multicolumn{3}{c}{ Secukinumab } \\
\cline { 2 - 4 } & $\begin{array}{c}300 \mathrm{mg} \text { s.c. } \\
(\mathrm{N}=100)\end{array}$ & $\begin{array}{c}150 \mathrm{mg} \text { s.c. } \\
(\mathrm{N}=100)\end{array}$ & $\begin{array}{c}75 \mathrm{mg} \mathrm{s.c.} \\
(\mathrm{N}=99)\end{array}$ \\
\hline ACR20 & 69.4 & 64.4 & 50.3 \\
ACR50 & 50.6 & 36.0 & 28.2 \\
ACR70 & 33.1 & 23.1 & 14.9 \\
a PASI 75 & 79.5 & 73.3 & 58.4 \\
aPASI 90 & 69.6 & 52.5 & 33.7 \\
SF-36 PCS, LS mean change from BL (SE) & $6.8(0.85)$ & $5.0(0.87)$ & $4.1(0.91)$ \\
DAS28-CRP, LS mean change from BL (SE) & $? 1.9(0.12)$ & $? 1.7(0.12)$ & $? 1.5(0.13)$ \\
HAQ-DI, LS mean change from BL (SE) & $? 0.58(0.05)$ & $? 0.48(0.06)$ & $? 0.27(0.06$ \\
b Resolution of enthesitis & 71.5 & 61.8 & 68.4 \\
${ }^{c}$ Resolution of dactylitis & 79.9 & 78.0 & 88.6 \\
\hline
\end{tabular}

${ }^{*} \%$ responders unless otherwise specified. ${ }^{a}$ Assessed in pts with psoriasis affecting $\geq 3 \%$ body surface area at $B L(300 \mathrm{mg}: n=41 ; 150 \mathrm{mg}: \mathrm{n}=58 ; 75 \mathrm{mg}: \mathrm{n}=50)$. ${ }^{\mathrm{b}}$ Assessed in pts $(\mathrm{n}=56[300$ $\mathrm{mg}], 64[150 \mathrm{mg}]$ and 68 [75 mg]) with this symptom at BL. ${ }^{c}$ Assessed in pts $(n=46$ [300 mg], 32 [150 mg] and 33 [75 mg]) with this symptom at BL. BL, baseline; DAS28-CRP, 28-joint disease activity score using $\mathrm{C}$-reactive protein; $\mathrm{HAQ}-\mathrm{DI}$, health assessment questionnaire-disability index; LS, least squares; N, number of pts randomised; PASI, psoriasis area and severity index; SE, standard error; SF-36 PCS, short form-36 physical component summary.

Conclusions: Secukinumab 300 and $150 \mathrm{mg}$ provided sustained improvements in signs and symptoms and multiple clinical domains of active PsA through 2 years of therapy. Secukinumab was well tolerated, with a safety profile consistent with that reported previously.

\section{References:}

[1] McInnes IB, et al. Lancet 2015;386:1137-46.

[2] McInnes IB, et al. Ann Rheum Dis. 2015;74:352-3.

Disclosure of Interest: I. McInnes Grant/research support from: Abbvie, Amgen, BMS, Celgene, Janssen, Lilly, Novartis, Pfizer, and UCB, Consultant for: Abbvie, Amgen, BMS, Celgene, Janssen, Lilly, Novartis, Pfizer, and UCB, Speakers bureau: Abbvie, Amgen, BMS, Celgene, Janssen, Lilly, Novartis, Pfizer, and UCB, P. Mease Grant/research support from: Abbvie, Amgen, BMS, Celgene, Crescendo Bioscience, Genentech, Janssen, Lilly, Merck, Novartis, Pfizer, UCB, Consultant for: Abbvie, Amgen, BMS, Celgene, Crescendo Bioscience, Genentech, Janssen, Lilly, Merck, Novartis, Pfizer, UCB, Speakers bureau: Abbvie, Amgen, BMS, Celgene, Crescendo Bioscience, Genentech, Janssen, Lilly, Merck, Novartis, Pfizer, UCB, C. Ritchlin Grant/research support from: Amgen, UCB, Abbvie,
Novartis, and Janssen, Consultant for: Amgen, UCB, Abbvie, Novartis, and Janssen, Speakers bureau: Amgen, UCB, Abbvie, Novartis, and Janssen, P. Rahman Consultant for: Abbott, Abbvie, Amgen, BMS, Celgene, Janssen, Novartis, Pfizer and Roche. Consultant for pharmaceutical companies dealing with biologic agents in rheumatology, A. Gottlieb Grant/research support from: (paid to Tufts Medical Center until 5/11/16 thereafter: None): Centocor (Janssen) Inc., Amgen, Abbott (AbbVie), Novartis, Celgene, Pfizer, Lilly, Levia, Merck, Xenoport, Dermira, Baxalta, Consultant for: Amgen Inc., Astellas, Akros, Centocor (Janssen) Inc., Celgene Corp., Bristol Myers Squibb Co., Beiersdorf Inc., Abbott Labs. (AbbVie), TEVA, Actelion, UCB, Novo Nordisk, Novartis, Dermipsor Ltd., Incyte, Pfizer, Canfite, Lilly, Coronado, Vertex, Karyopharm, CSL Behring Biotherapies for Life, Glaxo SmithKline, Xenoport, Catabasis, Meiji Seika Pharma Co. Ltd, Takeda, Mitsubishi, Tanabe Pharma Development America Inc., Genentech, Baxalta, Kineta One, KPI Therapeutics, Crescendo Bioscience, Aclaris, Amicus and Reddy Labs, B. Kirkham Grant/research support from: Abbvie, BMS, Celgene, Janssen, Lilly, MSD, Novartis, Roche, and UCB, Consultant for: Abbvie, BMS, Celgene, Janssen, Lilly, MSD, Novartis, Roche, and UCB, Speakers bureau: Abbvie, BMS, Celgene, Janssen, Lilly, MSD, Novartis, Roche, and UCB, R. Kajekar Shareholder of: Novartis, Employee of: Novartis, E. M. Delicha Employee of: Novartis, L. Pricop Shareholder of: Novartis, Employee of: Novartis, S. Mpofu Shareholder of: Novartis, Employee of: Novartis DOI: 10.1136/annrheumdis-2017-eular.1274

\section{OP0223 ABATACEPT IN THE TREATMENT OF ACTIVE PSORIATIC ARTHRITIS: 1-YEAR RESULTS FROM A PHASE III STUDY}

P. Mease ${ }^{1}$, A. Gottlieb ${ }^{2}$, D. van der Heijde ${ }^{3}$, O. FitzGerald ${ }^{4}$, A. Johnsen ${ }^{5}$ M. Nys ${ }^{6}$, S. Banerjee ${ }^{5}$, D. Gladman ${ }^{7} .{ }^{1}$ Swedish Medical Center and University of Washington, Seattle; ${ }^{2}$ New York Medical College, Valhalla, United States; ${ }^{3}$ Leiden University Medical Center, Leiden, Netherlands; ${ }^{4}$ St Vincent's University Hospital and University College Dublin, Dublin, Ireland; ${ }^{5}$ Bristol-Myers Squibb, Princeton, United States; ${ }^{6}$ Bristol-Myers Squibb, Braine-l'Alleud, Belgium; ${ }^{7}$ University of Toronto and Toronto Western Hospital, Toronto, Canada

Background: In the Phase III ASTRAEA trial (NCT01860976), abatacept (ABA), a selective T-cell co-stimulation modulator, significantly increased ACR20 response (primary endpoint; PE) and had an overall beneficial effect vs placebo (PBO) on musculoskeletal symptoms in patients (pts) with active psoriatic arthritis (PsA) at 24 weeks (W). ${ }^{1}$

Objectives: To analyse 1-year results from ASTRAEA.

Methods: Pts with active disease ( $>3$ swollen and $>3$ tender joints), $>2 \mathrm{~cm}$ target lesion of plaque psoriasis and inadequate response/intolerance to $\geq 1$ non-biologic DMARD were randomized (1:1) to SC ABA $125 \mathrm{mg}$ weekly or PBO for $24 \mathrm{~W}$, followed by open-label (OL) SC ABA up to $52 \mathrm{~W}$. Randomization was stratified by MTX use, prior TNF inhibitor (TNFi) use and skin involvement $\geq 3 \%$ of body surface area. Pts without $\geq 20 \%$ improvement in joint counts at $\mathrm{W} 16$ were switched to OL ABA (early escape; EE) for $28 \mathrm{~W}$ (total study time: $44 \mathrm{~W}$ ). Pre-specified exploratory endpoints included: ACR20/50/70 responses at W44; adjusted mean changes from baseline (BL) in DAS28 (CRP; post hoc analysis) and HAQ-DI at W44 and PsA-modified total Sharp/van der Heijde score (SHS) at W44 (EE pts)/W52 (non-EE pts); complete resolution of BL enthesitis and dactylitis at W44 (EE pts)/W52 (non-EE pts); and Psoriasis Area and Severity Index (PASI) 50/75 responses at W44. Analyses used the ITT population with non-responder imputation for missing values and actual data at each time point for all pts (denominator at each time point equal to number of pts in ITT population). All missing responses were imputed as non-responders, except if the missing value was between 2 visits for which the pt was a responder. In that case the missing value was imputed as a responder.

Results: Of 424 pts enrolled, 213 received $A B A$ and 211 PBO. Most (>60\%) pts had received prior TNFis. Of pts in the ABA and PBO groups, $76(36 \%$ and $89(42 \%)$ were EE, $12(6 \%)$ and $24(11 \%)$ discontinued by PE of W24;

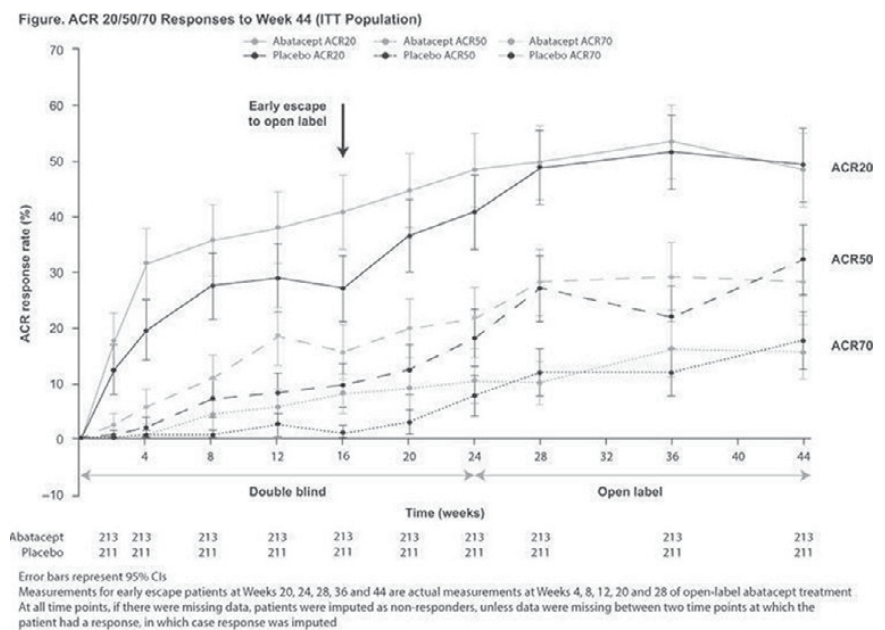


$197(92 \%)$ and $185(88 \%)$ entered the OL period, of whom $165(84 \%)$ and 162 $(88 \%)$ completed. At W44, ACR responses at W24 were maintained for pts who continued $A B A$, and improved for those who switched from PBO to ABA (Figure). Continued improvements in DAS28 (CRP) and HAQ-DI after W24 were seen for $\mathrm{ABA}$ and $\mathrm{PBO} / \mathrm{ABA}$ groups, with mean (SE) changes from $\mathrm{BL}$ to W44 of -1.81 $(0.09)$ and $-1.84(0.10)$ in DAS28 (CRP) (changes to W24 were -1.35 [0.10] and $-0.94[0.11]$ ) and $-0.37(0.04)$ and $-0.38(0.04)$ in HAQ-DI (changes to W24 were $-0.33[0.04]$ and $-0.20[0.05])$, respectively. There was minimal progression based on mean (SE) change from BL in PsA-modified total SHS at W44/52 in the ABA and PBO/ABA groups: $0.18(0.12)$ vs 0.30 (0.12). Complete resolution of $\mathrm{BL}$ enthesitis occurred in $48.6 \%$ and $43.9 \%$ and $B L$ dactylitis in $68.9 \%$ and $60.0 \%$ of pts with $A B A$ and $A B A / P B O$, respectively, at W44/52. At W44, for ABA and PBO/ABA, PASI 50 responses were $30.1 \%$ and $34.5 \%$; PASI 75 responses were $19.9 \%$ and $16.9 \%$. There were no new safety signals.

Conclusions: Responses were maintained across musculoskeletal endpoints up to 1 year in a relatively refractory population of pts continuing on SC abatacept. Abatacept was well tolerated.

\section{References:}

[1] Mease P, et al. Arthritis Rheumatol 2016;68(Suppl 10):Abstract 1041 Disclosure of Interest: P. Mease Grant/research support from: AbbVie, Amgen, Bristol-Myers Squibb, Celgene, Janssen, Lilly, Novartis, Pfizer, Sun, UCB, Consultant for: AbbVie, Amgen, Bristol-Myers Squibb, Celgene, Crescendo Bioscience, Corrona, Demira, Janssen, Lilly, Novartis, Pfizer, Sun, UCB, Zynerba, Speakers bureau: AbbVie, Amgen, Bristol-Myers Squibb, Celgene, Crescendo Bioscience, Genentech, Janssen, Novartis, Pfizer, UCB, A. Gottlieb Grant/research support from: Centocor (Janssen), Amgen, Abbott (AbbVie), Novartis, Celgene, Pfizer, Lilly, Coronado, Levia, Merck, Xenoport, Dermira, Baxalta, Consultant for: Amgen Inc.; Astellas, Akros, Centocor (Janssen), Inc.; Celgene Corp., Bristol-Myers Squibb Co., Beiersdorf, Inc., Abbott Labs. (AbbVie), TEVA, Actelion, UCB, Novo Nordisk, Novartis, Dermipsor Ltd., Incyte, Pfizer, Canfite, Lilly, Coronado, Vertex, Karyopharm, CSL Behring Biotherapies for Life, GlaxoSmithKline, Xenoport, Catabasis, Meiji Seika Pharma Co., Ltd, Takeda, Mitsubishi Tanabe Pharma Development America, Inc, Genentech, Baxalta, D. van der Heijde Consultant for: AbbVie, Amgen, Astellas, AstraZeneca, Bristol-Myers Squibb, Boeringer Ingelheim, Celgene, Daiichi, Eli-Lilly, Galapagos, Gilead, Janssen, Merck, Novartis, Pfizer, Regeneron, Roche, Sanofi, UCB, O. FitzGerald: None declared, A. Johnsen Employee of: Bristol-Myers Squibb, M. Nys Shareholder of: Bristol-Myers Squibb, Employee of: Bristol-Myers Squibb, S. Banerjee Shareholder of: Bristol-Myers Squibb, Employee of: Bristol-Myers Squibb, D. Gladman Grant/research support from: AbbVie, Amgen, Celgene, Janssen, Novartis, Pfizer, UCB, Consultant for: AbbVie, Amgen, BMS, Celgene, Eli Lilly, Janssen, Novartis, Pfizer, UCB DOI: 10.1136/annrheumdis-2017-eular.2865

\section{FRIDAY, 16 JUNE 2017 \\ From classics to new: synthetic DMARDs in RA}

\section{OP0224 SIMILAR SHORT TERM CLINICAL RESPONSE TO INITIAL TREATMENT WITH HIGH VERSUS LOW DOSE METHOTREXATE IN MONO- AND COMBINATION THERAPY IN EARLY RHEUMATOID ARTHRITIS PATIENTS}

S.A. Bergstra ${ }^{1}$, C.F. Allaart ${ }^{1}$, R. van den Berg ${ }^{1,2}$, A. Chopra $^{3}$, N. Govind ${ }^{4}$, T.W. Huizinga ${ }^{1}$, R.B. Landewé ${ }^{5,6}$ on behalf of METEOR working group. ${ }^{1}$ Rheumatology, LUMC, Leiden; ${ }^{2}$ Rheumatology, Erasmus University Medical Center, Rotterdam, Netherlands: ${ }^{3}$ Center for Rheumatic Diseases, Pune, India; ${ }^{4}$ University of the Witwatersrand, Johannesburg, South Africa; ${ }^{5}$ Amsterdam Rheumatology \& Immunology Center, Amsterdam; ${ }^{6}$ Zuyderland Medical Center, Heerlen, Netherlands

Background: Aiming at rapid decrease of disease activity, there has been a trend to start with higher doses of methotrexate (MTX) in newly diagnosed rheumatoid arthritis (RA) patients, both as monotherapy and in combination with other antirheumatic drugs (DMARDs). We hypothesized that in combination with other very effective medication, there might be no additional benefit of high over low doses of MTX.

Objectives: To compare early clinical response to high versus low doses of MTX in mono- and combination therapy in DMARD naive early RA patients.

Methods: RA patients included in the observational international METEOR cohort with symptom duration $\leq 5$ years, time between diagnosis and first visit $<2$ months, MTX prescribed as (part of) first treatment, no medication change within 3 to 6 months after treatment start and available outcome data on disease activity, were selected. Patients were divided into 4 medication groups: MTX monotherapy, MTX + synthetic (cs)DMARDs, MTX + oral glucocorticoid (+ possibly csDMARDs) or MTX + biologic (b)DMARDs (+ possibly csDMARDs). Missing data were imputed using multivariate normal imputation. MTX dose was dichotomized: low dose $\leq 10$ $\mathrm{mg} / \mathrm{week}$; high dose $\geq 15 \mathrm{mg} /$ week. A propensity score (PS) was calculated to adjust the relationship between MTX dose and outcome for potential confounding by indication. Linear mixed model analyses for DAS, DAS28, and HAQ were performed for each medication group, with MTX-dose and time (days between assessment visit and baseline assessment) as co-variates. Associations were adjusted for the PS. Random intercept and slope were used to account for irregular time intervals between visits.
Results: Patients who started on MTX monotherapy had lower baseline disease activity and fewer were erosive and autoantibody positive; other baseline characteristics were comparable between medication groups. The number of patients on combination therapy with bDMARDs was too small to perform analyses (26 visits in 11 patients). For patients starting on MTX monotherapy, MTX+csDMARDs or MTX+glucocorticoids, the PS-adjusted effects of MTX-dose (high vs low) on DAS, DAS28 and HAQ were small and not clinically meaningful. The unadjusted main associations between MTX-dose and outcomes were often in opposite direction and/or much larger than the PS adjusted associations, suggesting that confounding by indication indeed plays a role and that (at least some) correction was achieved by adjusting for the PS (table 1).

Table 1: Unadjusted and propensity score adjusted results of the linear mixed model analyses to investigate the effectiveness of high versus low methotrexate dose on dise ase activity (DAS and DAS28) and physical functioning ( $\mathrm{HAQ}$ ), stratified per medication group.

\begin{tabular}{|c|c|c|c|c|c|c|}
\hline \multicolumn{7}{|c|}{ Methotrexate monotherapy (n patients $=449, n$ visits $=975$ ) } \\
\hline & \multicolumn{2}{|l|}{ DAS } & \multicolumn{2}{|l|}{ DAS28 } & \multicolumn{2}{|l|}{ HAQ } \\
\hline & $\beta$ & $95 \% \mathrm{Cl}$ & $\beta$ & $95 \% \mathrm{Cl}$ & $\beta$ & $95 \% \mathrm{a}$ \\
\hline MTX-dose group PS adjusted & 0.052 & $-0.17 ; 0.28$ & 0.085 & $-0.24 ; 0.41$ & 0.043 & $-0.11 ; 0.20$ \\
\hline MTX-dose group unadjusted & -0.55 & $-0.71 ;-0.39$ & -0.19 & $-0.45 ; 0.071$ & 0.17 & $0.059 ; 0.28$ \\
\hline \multicolumn{7}{|c|}{ Methotrexate + csDMARDs (n patient $s=265, n$ visits $=574$ ) } \\
\hline & \multicolumn{2}{|l|}{ DAS } & \multicolumn{2}{|l|}{ DA528 } & \multicolumn{2}{|l|}{ HAQ } \\
\hline & $\beta$ & $95 \% \mathrm{Cl}$ & $\beta$ & $95 \% \mathrm{Cl}$ & $\beta$ & $95 \% \mathrm{a}$ \\
\hline MTX-dose group PS adjusted & 0.036 & $-0.26 ; 0.33$ & 0.0066 & $-0.39,0.41$ & -0.014 & $-0.21 ; 0.18$ \\
\hline MTX-dose group unadjusted & -0.19 & $-0.45 ; 0.071$ & -0.29 & $-0.65 ; 0.065$ & 0.080 & $-0.094 ; 0.25$ \\
\hline \multicolumn{7}{|c|}{ Methotrexate + oral glucocorticoid ( + -csDMARDs) (n patients $=485, \mathrm{n}$ visit $=1075$ ) } \\
\hline & \multicolumn{2}{|l|}{ DAS } & \multicolumn{2}{|l|}{ DAS28 } & \multicolumn{2}{|l|}{ HAQ } \\
\hline & $\beta$ & $95 \% \mathrm{Cl}$ & $\boldsymbol{\beta}$ & $95 \% \mathrm{Cl}$ & $\beta$ & $95 \% \mathrm{a}$ \\
\hline MTX-dose group PS adjusted & -0.017 & $-0.26 ; 0.22$ & -0.14 & $-0.45 ; 0.17$ & -0.023 & $-0.17 ; 0.12$ \\
\hline MTX-dose group unadjusted & -0.33 & $-0.50,-0.15$ & -0.64 & $-0.86 ;-0.41$ & 0.14 & $0.040 ; 0.25$ \\
\hline
\end{tabular}
mg/week and high dose $=15$ mg/week. Low dose is the r ference category.

Conclusions: In a daily practice derived database in DMARD-naive early RA patients, we found no early clinical benefit of high over low initial MTX doses, neither for MTX monotherapy nor for combination therapy with MTX and csDMARDs or glucocorticoids. This seems to contradict a general trend over time to start higher MTX-doses.

Disclosure of Interest: None declared

DOI: 10.1136/annrheumdis-2017-eular.1601

\section{OP0225 THE EFFECT OF A LOW VERSUS HIGH FIRST PRESCRIBED DOSE OF METHOTREXATE ON EULAR RESPONSE AT SIX MONTHS USING DATA FROM THE RAMS STUDY}

R. Davies, M. Lunt, A. Barton, K.L. Hyrich, S.M.M. Verstappen on behalf of RAMS co-investigators. Division of Musculoskeletal \& Dermatological Sciences, Centre for Musculoskeletal Research, University of Manchester, Manchester, United Kingdom

Background: Methotrexate (MTX) is one of the most commonly used drugs for the treatment of rheumatoid arthritis (RA). Recommendations by an international panel state that oral MTX should be started at $10-15 \mathrm{mg} /$ week, with escalation of $5 \mathrm{mg}$ every $2-4$ weeks up to $20-30 \mathrm{mg} /$ week (1). In the UK, practice varies in terms of the starting dose prescribed for MTX, likely because of a lack of published evidence on the importance of MTX dose on its efficacy and safety.

Objectives: To compare 6 month response to MTX in RA patients starting $7.5 \mathrm{mg} / \mathrm{wk}$ versus those starting a $15 \mathrm{mg} / \mathrm{wk}$.

Methods: Patients were recruited to the national, UK, multi-centre $(n=35)$ longitudinal observational Rheumatoid Arthritis Medication Study (RAMS), including patients starting MTX for the first time with complete DAS28 at baseline and six months were included in this analysis. Patients were categorized into EULAR non-responders, moderate responders or good responders. Patients were categorised into those starting a low dose of MTX ( $\leq 7.5 \mathrm{mg} / \mathrm{wk})$ (LM-group) or a high Table 1

\begin{tabular}{lccc}
\hline & LM-group $(\mathrm{n}=171)$ & HM-group $(\mathrm{n}=639)$ & $\mathrm{P}$ \\
\hline Age, years & $58(47-69)$ & $61(51-69)$ & 0.13 \\
Gender, \% female & 70 & 60 & 0.03 \\
Disease duration, months & $6(3-11)$ & $6(3-11)$ & 0.65 \\
Tender joint count & $7(3-13)$ & $5(2-11)$ & 0.05 \\
Swollen joint count & $5(2-9)$ & $5(2-10)$ & 0.62 \\
Physician VAS, mm & $47(27-67)$ & $33(18-50)$ & 0.0001 \\
Patient VAS, mm & $50(26-70)$ & $35(20-55)$ & 0.0001 \\
DAS28 score at baseline & $4.2(3.4-5.2)$ & $4.1(3.2-5.1)$ & 0.24 \\
DAS28 score at 6 months & $3.5(2.7,4.1)$ & $3.0(2.2,4.1)$ & 0.004 \\
HAQ score & $1.3(0.6-1.8)$ & $0.9(0.4-1.5)$ & 0.001 \\
Other nbDMARD use, $\mathrm{n}(\%)$ & $30(17)$ & $61(10)$ & 0.003 \\
EULAR response at 6 months, $\mathrm{n}(\%)$ & & & 0.09 \\
Non-responders & $50(45)$ & $184(42)$ & \\
Moderate responders & $36(32)$ & $108(25)$ & \\
Good responders & $26(23)$ & $145(33)$ & \\
Fully adjusted RRR $\left(95 \%\right.$ Cl) ${ }^{*}$ & & &
\end{tabular}

Fully adjusted RRR $(95 \% \mathrm{Cl})^{\star}$

Non-responders

Moderate responders

Good responders

Scores are median [IQR]
$2.65(1.37,5.14$

0.004 